\title{
“Telas de Aranha”: Vieira da Silva na poesia de Alberto de LACERDA
}

Paulo Alexandre PEREIRA*

\section{Resumo}

Propomos uma análise dos poemas que, na obra de Alberto de Lacerda (19282007), elegem como pretexto a personalidade artística ou a criação plástica de Maria Helena Vieira da Silva. Combinando reminiscência afetiva, tributo elegíaco e pulsão ecfrástica, os textos que o poeta de Oferenda dedica à pintora não são imunes ao discurso crítico que em torno da sua singularíssima obra foi sendo produzido, em âmbito artístico, e que, desde sempre, acentuou a sua consubstancial portugalidade.

Palavras-chave: Alberto de Lacerda. Maria Helena Vieira da Silva. Poesia. Pintura. Ekphrasis.

Em 1970, num artigo intitulado Vieira da Silva e a cultura portuguesa, notava José-Augusto França - desde cedo um dos mais entusiásticos divulgadores e intérpretes da pintura de Maria Helena Vieira da Silva que os estudos críticos que, até à data, tinham sido dedicados à sua pintura eram assinados,

[...] muito especialmente [por] poetas (Sophia de Mello Breyner, Alberto de Lacerda, Cesariny) [...] ou escritores (J. G. Simões, Ruben A, Eduardo Lourenço, M. Dionísio). [...] A atenção que, sobretudo, poetas e escritores portugueses dispensam a Vieira da Silva (eles que, tão raramente, ou quase nunca, estão atentos às artes plásticas...) é sem dúvida significativa de um entendimento a um nível não específico, que os intelectuais portugueses têm ou podem ter da pintura. (FRANÇA, 1970, p. 10)

Professor Associado da Universidade de Aveiro/UA, Aveiro, Portugal.

E-mail: ppereira@ua.pt Orcid iD: https://orcid.org/0000-0003-2539-4248 
Este "entendimento a um nível não específico" do originalíssimo imaginário plástico da criadora de "O Desastre", expresso na frequência com que, desde cedo, ele se tornou objeto de leituras não diretamente enfeudadas aos mais estreitos interesses disciplinares da estética ou da história da arte, é, de facto, revelador das afinidades literárias da sua pintura que se manifestam a, pelo menos, dois níveis: por um lado, na assiduidade com que são mobilizadas analogias literárias, quando se procura tornar inteligível uma obra que, logo em 1954, num artigo incluído nos Cadernos de Poesia, o mesmo França (2004, p. 133) tinha certeiramente definido como "pintura poética" ou "poesia plástica"; por outro, na fecunda interlocução crítico-criativa que Vieira estabeleceu com importantes figuras literárias, como Cecília Meireles e Murilo Mendes, com quem privará prolongadamente no decurso do seu exílio brasileiro, ou, já a partir de França - país ao qual que regressa em 1947 e onde acabará por se radicar -, com poetas portugueses como Sophia de Mello Breyner e Alberto de Lacerda. Por isso, se, como tem amplamente sublinhado a crítica, é inegável a dívida literária da pintura de Vieira da Silva, como aliás atestam as inúmeras parcerias que estabeleceu com escritores, não é surpreendente que tanto a sua notável obra plástica, como a sua singular personalidade artística tenham, em sentido inverso, instigado criativamente poetas que, como é o caso de Alberto de Lacerda, se tornaram também amigos. É justamente dos vestígios deixados pelo "trabalho aracniano" de Vieira da Silva, como o designou Rey (1969, n.p. apud FUNDAÇÃO CALOUSTE GULBENKIAN, 1970, p. 46) ${ }^{1}$, na obra poética do autor de Oferenda, que aqui tenciono ocupar-me, procurando esclarecer o lugar de evidente destaque que, num universo lírico filtrado pela reminiscência afetiva, como o de Alberto de Lacerda, marcado, por outro lado, por um esteticismo culturalista verdadeiramente omnívoro, o poeta reserva à obra e à figura da pintora.

\footnotetext{
"Toda a sua [de Veira da Silva] obra não é e senão a paciência transformada em rede, com a trama do ser na cadeia da existência, um trabalho aracniano exprimindo menos a emoção imediata ou a impressão bruta que o efeito em profundidade da emoção, do caminhar interior da impressão até ao limiar da consciência em que se realiza em espelhos, construções, perspectivas ou efeitos escalonados e múltiplos”.
} 
Radicado em Londres desde jovem, Lacerda conhece Vieira da Silva em 1959, por intermédio do pintor Jean Hugo - bisneto de Victor Hugo - que frequentava o seu "exótico círculo de amigos" e "lhe dá a conhecer a vida intelectual francesa” (RUIVO; SANTOS, 2009, p. 9). Entre ambos se virá a desenvolver uma amizade cúmplice que se prolonga até ao final da vida da pintora, e que incluía igualmente o pintor Arpad Szenes, marido de Vieira da Silva, de cuja vida e obra a sua própria se tornará praticamente indistinguível. Desta fecunda amizade a três (mas, sobretudo, das inúmeras afinidades que aproximaram poeta e pintora) não faltam manifestações de parte a parte. Com efeito, trata-se, como lembra Sousa (2009, p. 16), de “ [...] uma amizade bem documentada. Dela ficaram poemas, obras de arte, fotografias, cartas, registos de mil coisas partilhadas" (SOUSA, 2009, p. 16). De Lacerda, por exemplo, pintará Arpad Szenes 12 retratos, tendo-lhe o poeta, por seu lado, dedicado o volume Tauromogia (1981), evocando-o ainda no poema "Atelier de Arpad Szenes", incluído em Oferenda II (1994). A Vieira da Silva, dedicará Alberto de Lacerda o volume Palácio (vindo a lume em 1961 e, mais tarde, integrado em Oferenda I, de 1984), tendo-lhe, além disso, consagrado inúmeros textos de evocação e tributo, artigos e poemas. Um importante acervo epistolar, em larga medida ainda inédito, permite reconstituir o fecundo colóquio afetivo e intelectual que mantiveram pintora e poeta, um percurso que a exposição Alberto de Lacerda. Encontros de Vieira da Silva e Arpad Szenes, realizada em 2009, permitiu também cartografar².

Os encontros entre Vieira da Silva e Alberto de Lacerda foram, desde logo, ditados pelas contingências da biografia, compartilhando ambos tanto uma idêntica experiência de exílio ${ }^{3}$, como o desgosto suscitado

2 A exposição, com curadoria de Marina Bairrão Ruivo e Sandra Santos, esteve patente entre 2 de abril e 5 de julho de 2009, na Fundação Arpad Szenes-Vieira da Silva, em Lisboa, e divulgou abundantes testemunhos documentais e iconográficos sobre a amizade que uniu Alberto de Lacerda a Vieira da Silva integrados no espólio do poeta, presentemente depositado na Fundação Mário Soares.

3 Como argumenta Luísa Borges, “[...] poderemos distinguir cinco modos ou andamentos (para empregar uma terminologia mais próxima deste poeta) do exílio na poesia de Alberto de Lacerda: um exílio político, um exílio espacial, um exílio temporal, um exílio metafísico e, por último, um exílio interior”. (BORGES, 1990, p. 41) 
pela escalada dos regimes autoritários na Europa e, especialmente, em Portugal. A estas circunstâncias comuns não será decerto alheia a relação ambivalente que pintora e poeta, respetivamente à distância de Paris e de Londres, mantêm com uma pátria tornada evanescente pela memória ou mesmo nostalgicamente arcaica, mas de cuja paisagem - a de Lisboa, sobretudo ${ }^{4}$ - e legado cultural conservam viva lembrança, que assiduamente mobilizam como matéria-prima da criação. Como, referindo-se a Portugal, lembrava Alberto de Lacerda, em carta datada de 5 de outubro de 1970, dirigida a Vieira da Silva (1970 apud RUIVO; SANTOS, p. 56), "O país continua maravilhoso de se ver, mas só para ver" ${ }^{5}$. Mesmo ensombrado pela mágoa decetiva, este amor pela herança portuguesa (e a aguda consciência de ser ela instituinte da poiesis de ambos), conjuga-se, tanto na pintora como no poeta, com uma irrestrita afeição pelas artes, em geral, e pela música e pela literatura, em particular, à qual subjaz "[...] igualmente a convicção que tudo em arte se inter-relaciona” (SOUSA, 2009, p. 14). Por essa razão, ainda que Vieira da Silva e Alberto de Lacerda se apropriem e explorem criativamente, aliás com apurada consciência oficinal, distintas linguagens expressivas, é incontestável que nos dois artistas se deteta um coincidente

4 Justificando o destaque assumido pela cidade de Lisboa na obra plástica de Vieira da Silva, explica Ruivo (2019, n.p, tradução nossa) que “[...] "na sua [de Vieira da Silva] criação, a cidade da sua infância funcionou como uma metáfora dinâmica. As casas, as perspetivas, os labirintos, os azulejos são percetíveis na estrutura rítmica dos seus quadros. Enquanto cidade real, Lisboa encontra-se presente em inúmeros desenhos e telas, sendo frequentemente reproduzida de memória”. No original : “[...] dans sa [de Vieira da Silva] création, la ville de son enfance a agi comme une métaphore dynamique. Les maisons, les perspectives, les labyrinthes, les azulejos sont perceptibles dans la structure rythmique de ses tableaux. En tant que ville réelle, Lisbonne est présente sur d'innombrables dessins et toiles, souvent reproduite de mémoire".

Um análogo fascínio pela cidade atravessa a poesia de Alberto de Lacerda e, como justamente salientou Eduardo Lourenço, "poucos poetas terão invocado Lisboa, a cidade ainda provincial de há trinta anos ou a Lisboa mítica do nosso passado bárbaro e onírico como Alberto de Lacerda”. (LOURENÇO, 1987,n.p).

5 "Uma maravilha que aquele país infame não merece. Aquela maneira de viver, de ser, daquela gente - é degradante. São poucos os que se salvam. Uma miséria moral e espiritual. Eu já não já lá não ia há sete anos. O país continua maravilhoso de se ver; mas só para ver”. (grifo do autor) 
entendimento mistérico do ato de criação, venha ele a tomar corpo na tela ou no poema. Disso mesmo nos dá testemunho um passo do diário de Alberto de Lacerda, datado de 26 de julho de 1988, e redigido por ocasião de uma das suas regulares visitas à magnífica La Maréchalerie, a casacastelo de Yèvre-le-Châtel que Vieira partilhava com o marido ${ }^{6}$ :

\begin{abstract}
Ontem estávamos no atelier dela [de Vieira da Silva] a ouvir na rádio Boulez a ensaiar Le Marteau sans maitre com a destreza verbal que o caracteriza. Na minha frente, um pasmoso quadro branco, grande, em que a $\mathrm{M}$ [aria] $\mathrm{H}$ [elena] está a trabalhar. E de súbito escrevi dois poemas numa enorme concentração. Foi a primeira vez que trabalhei no atelier da $\mathrm{M}$ [aria] $\mathrm{H}$ [elena]. O facto de terem ali nascido dois poemas na frente dela tocou-a muito. Gostou deveras dos poemas. [...] Por vezes, olhava longamente para o quadro, grande, que eu crismei de Eurídice! É esse o título de um dos poemas. Disse-me que achava misteriosíssima a criação poética. É misteriosíssima para mim a criação de um quadro. (LACERDA,1988,n.p. apud RUIVO; SANTOS, 2009, p. 99 $)^{7}$
\end{abstract}

Não é, portanto, inesperado que a perceção deste mistério de parte a parte - atribuível ao proprium de pintura e poesia e à tensão paragónica entre palavra e imagem que dele deriva - regularmente se intrometa nas reflexões afetuosamente informais que tonalizam as trocas epistolares entre Alberto de Lacerda e Vieira da Silva. É sobretudo na pintora, que

6 Como explica Sousa (2009, p. 15), as visitas anuais de Alberto de Lacerda à casa de Yèvre-le-Châtel "eram estadias muito inspiradoras. Escrevia poemas, enchia folhas e folhas dos seus diários, e usando as suas palavras, 'atrevia-se' também a ir fazendo colagens que, 'com enorme topete', ia mostrar a Vieira”. São, efetivamente, inúmeros os poemas do autor que incluem a menção expressa de terem sido compostos no decurso dessas idílicas visitas à casa de Vieira da Silva/Arpad Szenes, formando, no volume Átrio, um verdadeiro ciclo lírico tematicamente polarizado em torno do genius loci da paisagem campestre francesa. Vd., por exemplo, o poema intitulado precisamente "Yèvre-le-Châtel": "Dias intensos/ Verdes/ Onde paira/ Refractada/ A eternidade". (LACERDA, 1997, p. 29)

7 Em conversa com Anne Philipe, Vieira da Silva reitera essa conceção mistérica da criação, aplicando-a especificamente à génese da obra plástica: "Um quadro é algo perfeitamente misterioso, e o modo como é feito também [...]”. (PHILIPE, 1995, p. 51) 
mais insistentemente se mostra ciente do défice expressivo da linguagem e reconhece a irremediável indigência das suas palavras, que esse projeto de concertação interartística parece avultar como aspiração confessa. Em carta a Alberto de Lacerda, datada de 18 de agosto de 1959, dando conta da sua leitura deslumbrada do livro 77 Poems que lhe fora enviado pelo poeta, confessa a pintora:

Li o seu livro logo depois da sua visita e tive uma alegria tão grande... A cada passo ia encontrando coisas maravilhosas e cada vez mais até ao fim: "Desde o centro da terra até ao infinito", "ou como Londres à tarde nos finais de Novembro". "Que a vela se esboroa por completo E o céu cobre, em palácio, o mundo inteiro". Eu gostava de pintar um quadro assim. (VIEIRA DA SILVA, 1959, n.p. apud RUIVO; SANTOS, 2009, p. 19)

Em carta de setembro de 1962, o desejo de pintar como quem escreve um poema será formulado, em versão revista, como projeto ecfrástico de pintar um quadro a partir de um poema:

[... o o seu poema é quase uma profecia, uma evocação, eu também queria nos meus quadros acordar e chamar qualquer coisa que falta a essas pedras. [...] Um dia farei um quadro inspirado no seu poema. [... ] Diante do cavalete falo imenso consigo Alberto, mas depois quando me encontro diante do papel não sei escrever, não sei encontrar as palavras exactas. (VIEIRA DA SILVA, 1962, n.p. apud RUIVO; SANTOS, 2009, p. 28)

Esta retração da palavra, que a pintura parece substituir, surgirá, ainda outra vez, expressa em carta datada de abril de 1974: "quando se pinta e desenha", reconhece Vieira da Silva, "as palavras fogem, ficam linhas e cores" (VIEIRA DA SILVA, 1974, n.p. apud RUIVO; SANTOS, 2009, p. 66).

No que diz respeito a Alberto de Lacerda, é sobejamente conhecido o seu fascínio pela pintura, de que foi infatigável colecionador, bem como o seu contacto estreito com o meio artístico, em torno do qual gravitavam, 
por exemplo, as pintoras e amigas Menez e Paula Rego, cujas primeiras exposições e subsequente carreira o poeta irá promover e acompanhar. Nesse eclético "mundo visual" de Lacerda coexistem, como notou McEwen (1987, n. p.), a "reverência em que ele tem o velho mundo e o deleite que lhe inspira o Novo", numa demonstração de um congregante ecumenismo estético, de cujas experiências formativas o poeta dá conta em carta dirigida ao mesmo crítico de arte:

A propósito da sua pergunta - qual foi a minha primeira revelação da pintura - embora eu tivesse consciência dela na minha adolescência, sobretudo através de reproduções, o primeiro choque sublime foram, como lhe disse, aos 17 anos, umas maçãs de Cézanne e umas bailarinas de Degas num museu muito mau de Joanesburgo. Depois, em Lisboa, liguei-me de amizade com vários pintores surrealistas. E houve outra grande revelação antes de eu vir para Londres em 1951 no Museu de Arte Antiga em Lisboa; só me lembro de um quadro: um Turner da última fase, da Tate Gallery. Deslumbrou-me esmagadoramente; embora uma representação realista de luz, pura luz - tinha, a par disso, uma qualidade transcendente. E depois, houve os Pieros da National Gallery (Londres): os quadros que mais me comovem no mundo inteiro são a Natividade e o Baptismo. Continuo a considerá-lo o maior dos pintores. Sim, admiro o livro de Clark, mas não quis dar a impressão de que tenho um ângulo literário para as artes (para a literatura, ainda menos). (LACERDA apud McEWEN, 1987)

A enfática admiração que Lacerda confessa a respeito de Piero della Francesa recomenda que nela nos detenhamos brevemente, por duas ordens de razões: por um lado, por ao genial pintor italiano do Quattrocento dedicar o autor, logo nos inaugurantes 77 Poems, uma "Homenagem a Piero della Francesca", antecipando, nesse gesto de louvor, o tributo poético que, anos mais tarde, virá a endereçar a Vieira da Silva; por outro, porque, ao aludir à conhecida monografia que Sir Kenneth Clark consagra ao pintor renascentista, Lacerda ressalva não subscrever um “ângulo literário” na abordagem das artes, assim se distanciando - para recuperar os termos em que José-Augusto França se referia ao interesse dos literati pela obra 
de Vieira - de um "entendimento a um nível não específico" da pintura. Regressarei, oportunamente, a este pronunciamento antiliterário, quando me ocupar dos poemas de Alberto de Lacerda diretamente inspirados pelas telas de Vieira da Silva. Por enquanto, importa-me destacar a presença de uma consistente linha de sentido ecfrástica, detetável na produção lírica do autor, muito para além das homenagens já antes mencionadas. É evidente que o diálogo intersemiótico entre poesia e pintura não constitui, na obra de Lacerda, estratégia compositiva fortuita, compaginando-se, antes, com um entendimento holístico e intercomunicante das artes, que explicará, igualmente, a assiduidade ainda maior com que nela comparece a ekphrasis musical, consonante com a sua confessa melomania.

Deste modo, são múltiplos os referentes visuais e pictóricos que se rastreiam em textos que titularmente intimam figuras de pintores ou evocam quadros individuais, como acontece, por exemplo, com os poemas "Picasso", "Poema intitulado Paula Rego", "The Weapons of War Perished. Quadro de Adrien de Menasce", de Oferenda II; "Anunciação - Rafael, Vaticano -“, "Seurat” e "Trabalhadores de Seurat”, de Átrio; ou "Natureza Morta”, de Horizonte. Para além de nos permitir circunscrever as suas afinidades eletivas no campo das artes plásticas (e não é, obviamente, casual que vários dos pintores poeticamente homenageados se encontrem, de igual modo, representados na impressionante coleção de arte que Lacerda foi diligentemente acrescentando ao longo da vida), estes poemas ecfrásticos demonstram que, na mesma linha do que argumenta Nancy (2015, p. 25, tradução nossa), também para o poeta de Oferenda a ekphrasis implica sobretudo uma "[...] fala nascida da imagem: não aquela que pode ser proferida a propósito dela mas aquela que ela própria nos propõe ou sugere" ${ }^{\prime}$. Deixando falar as imagens, ao invés de falar sobre elas, a ekphrasis responde, como acrescenta ainda Nancy, às questões "o que é que se dá a ver? O que é que nos diz num primeiro olhar? E como é depois

8 “[...] parole issue de l'image: non pas celle que nous pouvons prononcer à propos d'elle mais celle qu'elle nous propose ou suggère elle-même.” 
necessário ficar em silêncio e regressar à imagem...” (p. 26) ${ }^{9}$. Esse percurso da imagem silenciosa à imagem que fala por si, que só uma contemplação desonerada de todo o encargo analítico-interpretativo permite refazer, é o que exemplarmente se encontra ilustrado no poema que Lacerda compõe a partir da Anunciação, de Rafael:

Foi entre essas colunas que surgiu

A mãe predestinada

Do azul

Irrompeu o arcanjo

Formidável

Depondo

Seu olhar de amavio

No ventre da esperança. (LACERDA, 1997, p. 107)

É indiscutível que, apesar da regularidade com que esta pulsão ecfrástica se insinua na obra poética de Lacerda, nenhum outro pintor ou obra plástica nela conseguem rivalizar com Vieira da Silva, um protagonismo que o afeto e admiração irrestritos que o poeta votava à pintora e à sua criação amplamente justificam. Num texto sobre Vieira da Silva, intitulado Notas para um retrato, publicado em novembro de 1964, no Diário Popular, sustentava Lacerda (1964, p. 8): "Não conheço nenhum artista em que a obra se confunda tão maravilhosamente, tão misteriosamente, com a vida, com as horas, com a biografia quotidiana”. Esta indistinção entre a vida e a obra de Vieira da Silva permitirá compreender que Lacerda tenha, em igual medida, dedicado poemas à pintora e à sua pintura, numa sondagem bifocal de criadora e criação, tornando assim indistinguíveis o seu temperamento artístico e o seu universo plástico.

Na obra poética de Alberto de Lacerda, é, pois, possível discriminar dois grupos de composições inspiradas por Vieira da Silva, mesmo que

9 "qu'est-ce qui se donne à voir? Qu'est-ce que ça dit au premier regard? Et comment ensuite il faut se taire et revenir à l'image...” 
a linha divisória entre ambas nem sempre se revele nítida: um primeiro, predominantemente centrado na biografia artística e no irresistível sortilégio emanado da sua misteriosa personalidade criativa, que o poeta sintetiza nos epítetos eufóricos de "châteleine sublime, maga, magicienne, irmã de Camões” (LACERDA, 1966, n.p. apud RUIVO; SANTOS, 2009, p. 47); um outro, menos quantioso, de natureza propriamente ecfrástica, que elege como móbil o estilo pictural ou telas individuais de Vieira da Silva, demorando-se nos seus elementos construtivos e iconografia idiossincrática. Do comentário de alguns desses textos me ocupo agora.

Na carta datada de 5 de outubro de 1970, que Alberto de Lacerda envia de Londres a Vieira da Silva, logo após ter visitado “já não sei quantas vezes” a grande exposição retrospetiva da pintora na Fundação Calouste Gulbenkian, inclui o autor um poema inédito, que apresenta como homenagem "inspirada pela sua exposição", prometendo à amiga pintora: "um dia reúno os textos todos e faço um livrinho" (LACERDA, 1970, n. p. apud RUIVO; SANTOS, 2009, p. 56). A promessa nunca chegará a ser concretizada. A composição, intitulada "Partitura para a bem amada irmã", é paradigmática da lógica compositiva de vários dos textos poéticos que Lacerda dedica a Vieira, fazendo convergir, num registo de alusão oblíqua, biografemas avulsos e Leitmotive picturais, numa textualização confluente da sua vida e da sua obra. Reproduz-se abaixo esse poema inédito:

Partitura para a bem amada irmã

Eu queria tactear no escuro. Não acendam as luzes. Cecília, nem tu, não fales, agora.

Deixa-me sentir a humidade hedionda das paredes. É preciso não fugir a nada.

Deixa-me atravessar as salas do não-amor.

Deixa-me adivinhar o bafo da morte.

A sibila existe perto do Castelo.

Ela e eu falamos de ti. A cidade sangra.

O desastre já passou ou está para vir? 
A cidade é de maravilha, mas é cega.

E surda.

As tuas telas de aranha, vistas aqui, são suspiros sobre um cárcere desabitado.

Os presos ululam nos lugares geométricos do costume e nas ruas e na orla do mar.

Vamos desaparecendo lentamente. De séculos e séculos de sonho amargo, ficará muito pouco. Estas paredes brancas? E os teus sinais, pintora, numa hesitação certa de dança interminável.

A tua luz maravilhada que te canta nos dedos, a tua angústia que é êxtase - cobrem-nos os olhos de lágrimas.

A cidade diz que não te merece.

Mas não é por orgulho que partes, partes sempre.

(LACERDA, 1970, n.p. apud RUIVO; SANTOS, 2009, p. 57)

O biografismo cifrado do poema, habilmente combinado com alguns dos mitos pessoais de Lacerda, manifesta-se logo a partir do título: ao passo que a metáfora musical da partitura é indicativa da melomania que coligava pintora e poeta, o parentesco simbólico sugerido pelo epíteto afetuoso de "bem amada irmã" corresponde a um protocolo consensualizado de amizade de que outros textos dão também testemunho. Num poema de Horizonte, por exemplo, Vieira da Silva é tratada, em termos análogos, como "a irmã mais velha que ele não teve" (LACERDA, 2001, p. 40), num gesto alterizante - em resultado do qual o eu se dá a ler como um ele - muito comum na dicção de Lacerda. Que a interpretação do poema não dispensa o conhecimento de uma enciclopédia afetiva compartilhada por pintora e poeta comprova-o ainda a menção, logo no primeiro verso, a "Cecília”. Trata-se, naturalmente, de Cecília Meireles - amiga próxima de Vieira, desde os tempos do seu exílio no Brasil, desaparecida em 1964 -, cuja memória é, no poema, conjurada 
pelos amigos: "Ela e eu falamos de ti". Tornado permutável, o alocutário ao qual o sujeito poético se dirige é tanto essa ressurecta "Cecília", como, num segundo momento, a "sibila [que] existe perto do Castelo", perífrase críptica por meio da qual se alude a Vieira da Silva, a castelã de La Maréchalerie, cuja aura misteriosa Lacerda repetidamente associava a dons profético-divinatórios, apodando-a regularmente de sibila, fada ou maga, "half-fairy, half-witch", como lapidarmente a retratará no obituário que, em 1992, redige para o The Independent (LACERDA, 1992, p. 23).

Uma vez esboçada a moldura parabiográfica que enquadra o poema, o olhar do sujeito lírico desloca-se, em seguida, para as "telas de aranha" da pintora, sobretudo depois de formulada a interrogação que constitui o ponto de rotação do poema - "O desastre já passou ou está para vir?". Em premeditada anfibologia, o termo "desastre" convoca a icónica tela que Vieira da Silva pinta em 1942, assim justamente intitulada, e para a qual colhe inspiração nas catástrofes da guerra que alastrava na Europa. A referência à cidade que "é de maravilha, mas é cega" reenvia, por seu turno, para um dos motivos figurativos nucleares da sua pintura - o das "cidades imaginadas que se organizam em prédios, ruas e labirintos" (RUIVO, 2000, p. 12) -, à medida que outros traços distintivos da sua linguagem formal, como a representação abstrato-geométrica ou o tratamento lumínico das telas, são lateralmente evocados através das alusões aos "lugares geométricos do costume" e à "luz maravilhada". É, pois, uma figuração multímoda aquela que o poema de Alberto de Lacerda nos devolve de Vieira da Silva: nele, a irrepetível genialidade da sua obra plástica é estreitamente conivente com a personalidade ímpar da pintora - retratada, não raras vezes, no momento epifânico da sua própria criação - e com a subterrânea cumplicidade da amiga que se tornou irmã:

A fada

A irmã mais velha que ele não teve A fada

Surgindo inesperada em sua mente 
Graças a um objeto

Assim ela pintava

Um pormenor do passeio

Uma luz esguia ao longe muito ao longe

Uma recordação aflorando imperiosa

Desencadeava na tela

Um universo tão desconhecido

Que às vezes a assustava

A família que ele não teve

Era a fada

A bruxa

Chamavam-lhe bruxa

E ela ria

Seu riso de criança

A fada

Lançando à sua volta um véu de encantamento

Que parece não ter fim.

(LACERDA, 2001, p. 40-41)

A doença e morte da pintora, a 6 de março de 1992, darão lugar à composição de um conjunto de poemas que lhe são dedicados e através dos quais se torna possível reconstituir uma trajetória disfórica que abre com uma sombria premonição de mortalidade ("A V. S.", de Átrio), passa pelo hino fúnebre ("In Memoriam V.D.S., "V. S. em Paris", ambos inéditos) e culmina em evocações póstumas, de tonalidade melancolicamente elegíaca, como aquela que surpreendemos enxertada num poema em prosa, incluído em Horizonte:

Lembra-se de súbito da velha amiga, maga entre as magas, que um dia num café de uma pequena cidade francesa - lhe disse como adorava cafés, como adorava cidades. Adorava o bulício, as relações obscuras entre seres e objetos, entre estranhos. Na sua mente, nas suas telas, as cidades volviam arquiteturas bizarras, abstractas e não, aparecendo e desparecendo, como as vagas na praia. (LACERDA, 2001, p. 22) 
Previsivelmente, o "negrume/No poço/ Insondável” (LACERDA, 1992, n. p. apud RUIVO; SANTOS, 2009, p. 125) que, após a morte de Vieira, se abate sobre o poeta surge, em "V. S. em Paris", transposto para a cidade, por meio de um processo de refração de pathos que torna agora a urbe - outrora magnífica - irreconhecível, por ter desaparecido a maga que, com apaixonada persistência, a pintara:

V. S. em Paris

A cidade

Que reinventaste

É outra

Radicalmente

Ao fim de séculos percorridos

Em poucos dias

Só agora sabemos

Que para ti

$$
\text { Ó maga }
$$

A imortalidade era

Teres pintado o outro lado da morte

Vais surgindo

Inteira

(LACERDA, 1992, n.p. apud RUIVO; SANTOS, 2009, p. 126).

Como observa Clarridge (2015), embora a crítica tenda a conceber o género da écfrase, tanto na sua modalidade factual como nocional ${ }^{10}$, sob a ótica de um esteticismo a-histórico, ele constitui, de facto, "a hybrid genre between art and criticism that poets use to interrogate the value and function of images in their respective contexts" (2015, p. 2). Assim, argumenta ainda a autora, "ekphrastic poems $[\ldots]$ straddle the

10 A distinção estabelecida por John Hollander entre "actual and notional ekphrasis" (1995, p.

7) diz respeito ao diverso estatuto ontológico da obra de arte que o poema elege como objeto: no primeiro caso, trata-se de um referente real; no segundo, de obra imaginária e, portanto, sujeita às leis gerais da ficcionalidade literária. 
boundary between art and criticism, often using the genre to respond to the same issues that their contemporaneous art critics debated in prose" (CLARRIDGE, 2015, p. 1). Representação de uma representação, na écfrase repercutem-se, inevitavelmente, a cultura estética e os contextos artístico-historiográficos em que o poeta - sobretudo quando, como acontece com Alberto de Lacerda, ele tem contacto privilegiado com o meio das artes e com os discursos que em torno delas se produzem - se encontra imerso e de que se torna inevitável caixa de ressonância. Não é, portanto, de estranhar que, mesmo quando o poeta programaticamente anuncia prescindir de uma contemplação informada ou erudita da obra de arte, o discurso crítico se insinue no domínio da criação.

É justamente o que se verifica no caso do poema "O Filtro", dedicado a Vieira da Silva e incluído em Oferenda II. O título, enigmático e sem vínculo aparente com o corpo do texto, suscita, inevitavelmente, a perplexidade hermenêutica do leitor:

O Filtro

\section{A Vieira da Silva}

Sonho emergindo do concerto

Das rochas colocadas

(Pelos deuses?)

De uma certa maneira sobre a terra

As mãos recebem em sangue

A dança do universo

As casas contraditórias viajam

Numa luta sem fim

Iluminada

As mãos recebem transparentes

A dança do universo

(LACERDA, 1994, p. 273) 
Na realidade, "O Filtro" reedita um símile a que a própria Vieira da Silva recorrera no prefácio do catálogo da exposição que, em 1963, realiza na galeria de arte de Jeanne Bucher. Nesse texto, a artista confessava a sua "[...] ambição desmesurada de dar ao mundo algo que fosse (perdoemme) como um filtro de amor" (WEELEN, 1973, p. 54, tradução nossa) ${ }^{11}$. $\mathrm{O}$ motivo do filtro de amor que, por intermediação artística, se quer oferecer ao mundo - aliás evocativo da natureza feérica frequentemente atribuída à pintora - encontra, no poema, correspondência no projeto de representar a "dança do universo", através da mão que pinta, redimindo, nesse gesto de denúncia e reparação, o mal do mundo.

É esta mesma citação da pintora que encerra o poema "Vieira da Silva”, também integrado em Oferenda II. Em estilo de diálogo dramático, em que interagem as vozes do sujeito poético que interpela e da pintora que responde, revisitam-se o processo criativo e os temas obsidiantes de Vieira da Silva, nele interpolando, em afetuosa homenagem intertextual, palavras de Cecília Meireles ${ }^{12}$ - a "amiga morta" - e da própria pintora:

- Onde te encontras?

- Na passagem de rosto para rosto, de cidade para cidade, de cataclismo para cataclismo, de encantamento para encantamento. Eu sou a que viaja. Tenho o nome que uma amiga morta se deu a si própria: SERENA DESESPERADA.

- E o amor?

- Nas pontes perigosas de rosto para rosto, de cidade para cidade, de ameaça para ameaça, do terror para a beleza, da beleza para a compaixão.

- Quem és tu, peregrina?

- L'ambition démésurée de donner au monde quelque chose qui serait (excusez-moi) comme um filtre d'amour. (LACERDA, 1994, p. 262, grifo do autor)

11 “[...] ambition démesurée de donner au monde quelque chose qui serait (excusez-moi) comme un philtre d'amour".

12 O epíteto "SERENA DESESPERADA" é utilizado por Cecília Meireles, grafado em maiúsculas, no poema "Epitáfio da Navegadora” (MEIRELES, 2006, p. 95), incluído em Vaga Música (1942), e tornou-se, a par do de "pastora de nuvens", um dos seus cognomes poéticos. 
Apesar de uma intenção declarada de recusar um "ângulo literário para as artes", nem por isso Alberto de Lacerda deixará de reinterpretar poeticamente a obra de Vieira à luz de uma hermenêutica artística já cristalizada em torno da sua obra, cujos contornos decerto conhece, e que irá reconverter sob espécie lírica. Esta contaminação crítica do discurso ecfrástico torna-se especialmente evidente no poema "Homenagem a Maria Helena Vieira da Silva", datado de 8 de novembro de 1961, e originalmente publicado em Palácio.

A atenção focal do sujeito oscila, agora, entre a observação da superfície pictórica de uma tela arquetípica, não nomeada - mas que poderia perfeitamente identificar-se com qualquer uma das muitas de Vieira em que comparecem os seus emblemáticos "ladrilhos" -, dando, logo depois, lugar a uma distendida descriptio laudatória da sua criadora. A breve secção ecfrástica que abre o poema presentifica, sem convocar um quadro específico, o inconfundível idioleto plástico da pintora. Sem referente pictórico assumido, bem poderia bem ter sido inspirada pela célebre tela La Machine Optique, que Vieira pinta em 1937:

Súbito a curva dos ladrilhos lança

Todos os deuses para o precipício

Donde voltam irreconhecíveis

Nessa geometria súbito inclinada

Vaga mavórtica duna placidíssima

Nessa geometria sem peso e sem perfídia

Passam os silêncios as mortes os mundos

De estrela para estrela jamais navegados

A maravilha das estalactites cruzando

O fundo dos mares

Sigla dos homens

Aceno dos deuses

Viagem perpétua (LACERDA, 1984, p. 212)

Tratando-se de um tributo poético, é natural que seja o panegírico imagisticamente exuberante da artista a polarizar a elocução lírica. Numa sintaxe enumerativa e assindética, o poema multiplica epítetos 
de sentido hiperbolizante, segundo a retórica do incrementum, fundido, num nivelamento paratático que parece aproximar as superfícies poética e pictórica, atributos relativos tanto à pintora, como à sua pintura:

\author{
Sereia diamante \\ Deméter coroada \\ De espinhos e louros \\ Mártir redimindo \\ Os lodos mas livre \\ $\mathrm{Na}$ mais bela crista \\ Do mais belo gesto \\ Pureza de fonte \\ Fonte de pureza \\ $[\ldots]$ \\ Deusa do espaço \\ Deusa da terra \\ Deusa que um deus \\ Deixou na infância \\ Dentro de caverna \\ Crivada de jóias \\ (LACERDA, 1984, p. 212-213)
}

Dir-se-ia que, na sua proliferação amplificante, o poema quer duplicar processualmente a arquitetura fragmentária e o geometrismo reticular que tornam inconfundível a pintura de Vieira da Silva, para isso contribuindo o processo retórico da sístrofe que estruturalmente o conforma - isto é, a listagem exaustiva de características que não desembocam em qualquer definição conclusiva. Num terceiro momento do texto - aquele em que mais distintamente a ekphrasis se acerca da crítica de arte -, o retrato que da pintora se esboça acentua o seu olhar duplo de exilada ("Teu olhar arrasta/ Nos espelhos lindos/ O Tejo e o Sena”, "Teu olhar arranca/ A música mais funda/ Mais forte intangível/ Do Tejo e do Sena”), para destacar, logo depois, a sua intrínseca portugalidade:

Quem te definiu

Portuguesa maga?

$[\ldots]$

Irmã de Camões 
Maravilha fatal

Da nossa idade

Redentora heroica

Duma raça triste

Ó majestosa

Senhora guardando

Nossa glória alta

O troféu da luz

O deslumbramento

Que mais nos faltava

No século negro

Ó guarda serena

Dum monumental

Trágico e sublime

Segredo que esplende

Para toda a parte

Como o sol que brilha

Apesar de tudo

Na tua pátria o mundo

E em Portugal

(LACERDA, 1984, p. 214-215)

Nas já antes mencionadas "Notas para um retrato", redigidas três anos depois de ter composto o poema, Lacerda recuperará, desta vez em modo crítico-interpretativo, alguns dos loci que aqui surgiam já associados à personalidade e obra da pintora, designadamente o seu parentesco espiritual com Camões e o universalismo "profundamente português" da sua pintura:

Os seus parentes portugueses: Fernando Pessoa, Camões, Bernardim, Fernão Lopes, Camilo.

Os seus parentes na pintura portuguesa? Mas como ter parentes numa família que não existe?

$[\ldots]$

Não conheço ninguém mais profundamente português do que Vieira da Silva. Não conheço ninguém menos português. (LACERDA, 1961, p. 8) 
Na enfatização desta consubstancial portugalidade da pintura de Vieira da Silva não se encontrava Lacerda desacompanhado. A centralidade temática e a relevância imaginária que nela assume a cultura portuguesa foi, desde cedo, reconhecida por críticos pioneiros, como José-Augusto França, que, no já citado "Vieira da Silva e a cultura portuguesa", argumenta:

Sabemos já que a paisagem urbana de Lisboa, com seus azulejos e seus sóis, pôde ser um motor metaforizante na criação de Vieira da Silva. As "casas" e as "perspectivas" decifráveis na estrutura rítmica da sua pintura têm uma certa memória, ou uma certa saudade, lisboeta - e levam em si a parte nacional que todo o grande criador possui, ou que possui todo o criador que seja grande. A "Espanha" de Picasso ou a "Rússia" de Kandinsky ou a "Itália" de Magnelli são constantes estruturais que têm correspondência no "Portugal" de Vieira. (FRANÇA, 1970, p. 10)

Esta mesma presença de um Portugal entrevisto pela saudade torna-se inteligível numa outra "Homenagem a Vieira da Silva", também incluída em Oferenda II, cujo subtítulo parentético esclarece tratar-se de um "cadavre exquis de colaboração com Octavio Paz". Com o escritor mexicano manteve Alberto de Lacerda amizade próxima, o que explica este curioso exercício de escrita colaborativa. Facilmente a estrutura bilíngue do poema permite identificar os versos que nele são atribuíveis a cada uma das mãos: assim, se Paz escolhe sobretudo recortar da pintura de Vieira consabidos emblemas iconográficos (as casas, as bibliotecas ou os olhos, num claro reenvio para o quadro homónimo "Les Yeux", de 1937), Lacerda insiste, de novo, na linhagem irrecusavelmente portuguesa da pintora, irmanando-a, desta vez, a Fernando Pessoa:

\author{
De Pessoa a Vieira da Silva \\ (frase larga e precisa) \\ Una geometría de cometas \\ Rasgando o manto que flutua \\ Constelaciones de casas \\ Interrupções nostalgias \\ Libros nómadas \\ Que se encontram e desencontram \\ En una tela en unos ojos \\ (LACERDA, 1994, p. 274)
}


Por fim, incluído em Átrio, um poema intitulado "Projecto de tapeçaria para a capela da Embaixada Francesa em Lisboa” adota como estímulo pictórico uma pequena tela que Vieira da Silva oferece a Alberto de Lacerda, em circunstâncias que o poeta relata no seu diário e que aqui vale a pena relembrar:

De repente [Vieira da Silva] começa a ficar muito vaga e sonhadora, calada. Eu pergunto-lhe o que se passa. "Eu queria oferecer-lhe qualquer coisa”. Protesto. Vai desencantar uns seis quadros pequenos e dá-me a escolher. Escolhi uma pequena tela majestosa de 1981, e que é um estudo para uma tapeçaria destinada à capela da embaixada de França em Lisboa. A tapeçaria nunca chegou a ser feita. A tela - uma perfeita maravilha. (LACERDA, 1991, n. p. apud RUIVO; SANTOS, 2009, p. 105)

\section{Projecto de Tapeçaria para a Capela da Embaixada}

Francesa em Lisboa

\section{- Tela de Vieira da Silva}

FIgURA 1

Teinture De Lumière (1981)

Colunas

Estrias

De cor

Veias sustentando

O palácio

O templo

Colunas muito altas

Na transparência poderosa

Da cor

Veias multicolores

Corpo do universo

Ao cimo

Uma cruz diáfana

Caravela

Do sofrimento (LACERDA, 1997, p. 129)
Tela/Óleo

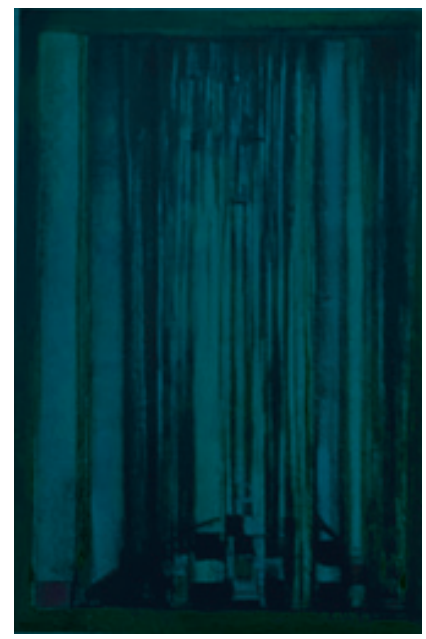

Fonte: RUIVO; SANTOS, 2009, p. 105. 
Totalmente magnetizado pela superfície da tela que meticulosamente explora, o olhar do sujeito observador começa por, em repetidas investidas descritivas, fixar os seus elementos compositivos (formas, cores, disposição no espaço), investindo-os, em simultâneo, de uma funcionalidade que é menos plástica do que poética: assim, as "colunas" sustentam "o palácio/ o templo" (termos afetados por uma semântica fortemente sobredeterminada na poesia de Lacerda) e as "veias", em extensão cósmica, percorrem o "corpo do universo". A essa função poético-imaginária da verticalidade das formas acede-se através do exercício de um olhar oblíquo e metamórfico: só ele permite ver estrias e veias onde estão colunas e vislumbrar numa "cruz diáfana" a "caravela do sofrimento", referência que inscreve, no poema, a memória vestigial da História Trágico-Marítima, que tão fundamente impressionou Vieira ${ }^{13}$.

$\mathrm{Na}$ evocação póstuma que, logo depois do desaparecimento de Vieira, publica no Jornal de Letras, garante Lacerda (1992, p. 11): "Não, não estou a idealizar. Foi um privilégio único ter conhecido de perto a sua personalidade humana tão incompreensivelmente rica, profunda, facetada”. Dessa excecional personalidade nos deixa vivo testemunho o conjunto de textos com que o autor pinta poeticamente os múltiplos rostos da artista das "telas de aranha", sem que, nesse retrato lírico afetivamente contaminado, consiga verdadeiramente desenredar o que nela foi o singular ser humano, a amiga cúmplice e a criadora genial. Afinal, como bem se lembra no brevíssimo poema "Arcano", "A amizade canta. Não descreve”. (LACERDA, 1984, p. 121)

\section{“Cobweb canvas”: Vieira da Silva in Alberto de Lacerda's poetry}

\section{ABSTRACT}

In this article, we seek to analyze the poems which Alberto de Lacerda (19282007) composed by drawing inspiration from either the artistic personality or the artwork of Maria Helena Vieira da Silva. Combining affectionate reminiscence,

13 Como bem documenta a célebre tela História Trágico-Marítima ou Naufrage (1944). 
elegiac tribute and ekphrastic impulse, the poems in which Lacerda evokes Vieira are not immune to the critical discourse pertaining to her remarkable work, in which her consubstantial Portugueseness is repeatedly emphasized.

Keywords: Alberto de Lacerda. Maria Helena Vieira da Silva. Poetry. Painting. Ekphrasis.

“Telas de araña”: Vieira da Silva en la poesía de Alberto de Lacerda

\section{RESUMEN}

En el presente artículo, nos proponemos llevar a cabo un análisis de los textos que, en la obra poética de Alberto de Lacerda (1928-2007), abordan expresamente la personalidad artística o la creación plástica de la pintora Vieira da Silva. Combinando reminiscencia afectiva, tributo elegíaco y pulsión ecfrástica, los textos que el poeta de Oferenda dedica a Vieira da Silva no son inmunes al discurso crítico que, en el ámbito artístico, se produjo en torno a su obra singular y que siempre ha acentuado su consustancial portugalidad.

Palabras-clave: Alberto de Lacerda. Maria Helena Vieira da Silva. Poesía. Pintura. EKrhrasis.

\section{REFERÊNCIAS}

BORGES, Luísa Manuela Quirino Rosa da Cunha. Alberto de Lacerda: arte amorosa, arte poética. 1990. 157 f. Tese (Mestrado em Literatura e Cultura Portuguesas) - Faculdade de Ciências Sociais e Humanas, Universidade Nova de Lisboa, Lisboa, 1990.

CLARRIDGE, Laura. Why They Are Not Painters: Ekphrasis and Art Criticism in the Twentieth Century. 2015.215 f. Tese (Doutorado) - Department of English, University of Toronto, Toronto, 2015.

FRANÇA, José-Augusto. Vieira da Silva e a cultura portuguesa. Colóquio: Revista de Artes e Letras, n. 58, p. 6-17, abr.1970.

FRANÇA, José-Augusto. Da poesia plástica. In: CARLOS, Luís Adriano; FRIAS, Joana Matos (ed.). Cadernos de poesia. Porto: Campo das Letras, 2004. p. 133134. (Edição fac-similada). 
FUNDAÇÃO CALOUSTE GULBENKIAN (ed.). Catálogo da Exposição Vieira da Silva. Lisboa: Fundação Calouste Gulbenkian, 1970.

HOLLANDER, John. The Gazer's Spirit: Poems Speaking to Silent Works of Art. Chicago: University of Chicago Press, 1995.

LACERDA, Alberto de. Notas para um retrato. Diário Popular, n. 24, p. 8, 1964.

LACERDA, Alberto de. Oferenda I. Lisboa: Imprensa Nacional-Casa da Moeda, 1984.

LACERDA, Alberto de. Vieira da Silva: obituaries. The Independent, 9 março 1992, p. 23.

LACERDA, Alberto de. Vieira da Silva, um grande ser humano. Jornal de Letras, Artes e Ideias, p. 11, 10 março 1992.

LACERDA, Alberto de. Oferenda II. Lisboa: Imprensa Nacional-Casa da Moeda, 1994.

LACERDA, Alberto de. Átrio. Lisboa: Imprensa Nacional-Casa da Moeda, 1997.

LACERDA, Alberto de. Horizonte. Lisboa: Imprensa Nacional-Casa da Moeda, 2001.

LOURENÇO, Eduardo. Alberto de Lacerda. Uma poética do exílio redimido. In: FUNDAÇÃO CALOUSTE GULBEKNIAN. Alberto de Lacerda: o mundo de um poeta. Lisboa: Centro de Arte Moderna: FCG, 1987.

McEWEN, John. O mundo visual de um poeta. In: FUNDAÇÃO CALOUSTE GULBEKNIAN. Alberto de Lacerda: o mundo de um poeta. Lisboa: Centro de Arte Moderna: FCG, 1987.

MEIRELES, Cecília. Viagem \& Vaga Música. Rio de Janeiro: Nova Fronteira, 2006.

NANCY, Jean-Luc. Ekphrasis. Études Françaises, v. 51, n. 2, p. 25-35, 2015.

PHILIPE, Anne. O fulgor da luz. conversas com Maria Helena Vieira da Silva e Arpad Szenes. Tradução Luiza Neto Jorge. Lisboa: Edições Rolim, 1995.

RUIVO, Marina Bairrão. Vieira da Silva. In: ARPAD SZENES/VIEIRA DA SILVA. Aveiro: Câmara Municipal, 2000. p. 9-13.

RUIVO, Marina Bairrão. Lisbonne - Paris, les villes de Maria Helena Vieira da Silva. Reflexos: Revue Pluridisciplinaire du Monde Lusophone, n. 4, maio 2019. 
Disponível em: http://revues.univ-tlse2.fr/reflexos/index.php?id=541. Acesso em: 12 jul. 2020.

RUIVO, Marina Bairrão; SANTOS, Sandra (coord.). Catálogo da Exposição Alberto de Lacerda: encontros com Vieira da Silva e Arpad Szenes. Lisboa: Fundação Arpad Szenes-Vieira da Silva, 2009.

SOUSA, Luís Amorim de. Vieira, Arpad e Alberto. In: RUIVO, Marina Bairrão; SANTOS, Sandra (coord.). Catálogo da Exposição Alberto de Lacerda encontros com Vieira da Silva e Arpad Szenes. Lisboa: Fundação Arpad Szenes-Vieira da Silva, 2009. p. 13-16.

WEELEN, Guy. Vieira da Silva. Paris: Fernand Hazan Éditeur, 1973.

Submetido em 20 de julho de 2021

Aceito em 27 de abril de 2021

Publicado em 30 de maio de 2021 